\title{
Social support status and the affecting factors in pregnant women $^{1}$ \\ Gebelerde sosyal destek durumu ve etkileyen faktörler
}

\author{
Belma Toptaş ${ }^{2}$ \\ Hilmiye Aksu ${ }^{3}$ \\ Sevgi Özsoy 4 \\ Tuğba Dündar ${ }^{5}$
}

\section{Abstract}

This study aimed to determine the social support status and the influencing factors in pregnancies. A total of 350 pregnant women who attended the nonstress test polyclinic of a state university participated in the descriptive study. The data collection tools of the study are the personal questionnaire and the Multidimensional Perceived Social Support Scale. Data analysis was done by percentage ratios, arithmetic mean, standard deviation, Kruskal Wallis Variance analysis and Mann Whitney $\mathrm{U}$ tests.

$38.3 \%$ of the pregnants are in the $20-24$ age group and the gestational week is $35.4 \pm 2.7$ $(\min -\max =29-40)$. Most pregnant women want to share their pregnancy first with their wives, that their spouses provide the most support during pregnancy, and that they should be with their partner during birth. The average multi-dimensional perceived social support score of pregnants is $59.60 \pm 15.9$. The mean scores of the family subscale of the

\section{Özet}

$\mathrm{Bu}$ çalışmanın amacı gebelerin sosyal destek durumunu ve bu durumunu etkileyen faktörleri belirlemektir. Tanımlayıc1 olarak yapılan çalışmaya bir Devlet Üniversitesi'nin Non Stres Test polikliniğine gelen toplam 350 gebe katılmıştır. Kişisel soru formu ve Çok Boyutlu Algilanan Sosyal Destek Ölçeği ile veriler toplanmıştır. Verilerin analizi standart sapma, yüzdelik oranlar, aritmetik ortalama, Kruskal Wallis Varyans analizi ve Mann Whitney U testleri ile yapılmıştır.

Gebelerin \%38,3’ü 20-24 yaş grubundadır ve gebelik haftası 35,4 $\pm 2,7$ ( $\min -\max =29-40$ )'dir. Gebelerin çoğu en fazla desteği eşlerinden aldıklarını ve doğum sırasında eşinin yanında olmasını istemiştir. Gebelerin algılanan sosyal

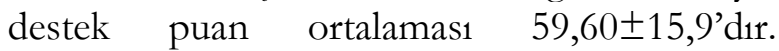
Gebelerin sosyal destek ölçeğinin alt boyut ortalamalarından aile puan ortalaması, arkadaş ve özel insan puan ortalamasından yüksek bulunmuştur. Gebelerin yaşı ile sosyal destek ölçeği alt boyutları arasında bir ilişki

\footnotetext{
${ }^{1}$ This research was presented as a verbal presentation at the I. Adnan Menderes University Health Sciences Congress between June 29-July 1.

2 Research Assistant., Adnan Menderes University, Faculty of Nursing, Obstetrics and Gyneocologic Nursing Department, belma toptas1@hotmail.com

3 Professor, Adnan Menderes University, Faculty of Nursing, Obstetrics and Gyneocologic Nursing Department, hilmiyeaksu@yahoo.com

${ }^{4}$ Associate Professor, Adnan Menderes University, Faculty of Nursing, Obstetrics and Gyneocologic Nursing Department, sevgiozsoy09@gmail.com

5 Research Assistant., Adnan Menderes University, Faculty of Nursing, Obstetrics and Gyneocologic Nursing Department, tugbadndr@gmail.com
} 
Toptaş, B., Aksu, H., Özsoy, S. \& Dündar, T. (2019). Gebelerde sosyal destek durumu ve etkileyen faktörler. Journal of Human Sciences, 16(3), 736-745. doi:10.14687/jhs.v16i3.5618

multidimensional perceived social support scale of the pregnants were higher than the average of the total scores of the friends and the special human sub-dimensions. There was no relationship between age of pregnancies and social support scale sub-dimensions ( $p>0.05)$. A relationship was found between the educational status of the pregnant women and the social support scale sub-dimensions ( $p$ $<0,05)$. There was a relationship between the education level of the spouse education and the social support points perceived from friends and private people $(\mathrm{p}<0,05)$. There was a relationship between the incomes of pregnant women and social support points perceived by family and friends $(p<0,05)$.

It has been seen that the level of social support of pregnant women is above the middle level and the most social support provided by their families. The level of receiving social support for pregnant women is positively affected by the education and working conditions of pregnant women and their spouses.

Keywords: Social support; pregnancy; spouses.

(Extended English summary is at the end of this document) saptanmamıştır $(p>0,05)$. Gebelerin eğitim durumu ile sosyal destek ölçeği alt boyutları arasında bir ilişki saptanmıştır $(p<0,05)$. Eş eğitim ve gebelerin çalışma durumu ile arkadaş ve özel insan sosyal destek puanı arasinda bir ilişki saptanmıștır $(p<0,05)$. Gebelerin gelir durumu ile aile ve arkadaş sosyal destek puanı arasında bir ilişki bulunmamıştır $(p<0,05)$.

Çalışmaya alınan gebelerin sosyal destek düzeyinin ortanın üstünde olduğu ve en fazla sosyal desteği ailelerinden sağladıkları görülmüştür. Gebelerin sosyal destek alma düzeyleri gebe ve eşlerinin eğitim ve çalışma durumlarından olumlu yönde etkilenmektedir.

Anahtar Kelimeler: Gebelik; sosyal destek; eş; aile; özel insan.

\section{Giriş}

Sosyal destek doğumdan ölüme kadar birçok yaşam değişikliğinde, bireye çevresindeki insanlar tarafından yapılan yardım olarak ifade edilmiştir. Bu yardım aile, arkadaşlar ve birey için anlamlı diğer kişilerden (akraba, komşu, doktor vb.) sağlanır (Eker ve Arkar, 2001). İnsan tüm yaşamı boyunca destek sistemlerine ihtiyaç duyar. Gebelik ve doğum sonrası dönem sosyal desteğe gereksinim duyulan en önemli dönemlerden biridir (Yıldırım, 1997). Gebelik dönemi fizyolojik değişikliklerle beraber, psiko-sosyal değişimlerin yaşandığ1 süreçtir. Gebelerin gebeliğin trimestirlarına göre farklı psiko-sosyal değişikler yaşamaktadır. Gebeliğin ilk trimesterinde kadınlar; neşe, mutluluk, üzüntü gibi duygular yaşayabilmektedir. Aynı anda mutluluk-üznütü gibi zıt (ambivalan) duygular bu dönemde sık yaşanmaktadır. Gebeliğin ikinci trimestırında ise fetüsü kabullenme ve bulantı, kusma gibi gebelik yakınmalarının azalmasına bağlı bir rahatlık sözkonusudur (Timur ve Şahin, 2010). Gebeliğin üçüncü trımestirinde ise, doğumun yaklaşmasına bağlı doğuma yönelik kayg1 ve doğum korkusu daha sık yaşanmaktadır. Gebeliğin hangi trımestırında olursa olsun, gebeler gebelik döneminde sosyal desteğe ihtiyaç hissetmektedir (Aktaş ve ark., 2015). Sosyal destek azlığı, gebelik ve lohusalık depresyonuna da neden olmaktadır. Aktaş ve ark. 266 gebe ile yaptıkları çalışmasında (2015); sosyal desteği az olan gebelerin, daha fazla gebelik depresyonu yaşadığı saptanmıştır. Aynı çalışmada eş desteği az olanların, depresyon puanının daha yüksek olduğu saptanmıştır (Aktaş ve ark, 2015). Sosyal destek alan kadınlar gebeliği daha iyi geçirmekte ve anne olmayı daha hızlı kabullenmektedirler. Sosyal destek sayesinde gebeler daha az sorun yaşamaktadırlar (Okanlı vd, 2003). 
Toptaş, B., Aksu, H., Özsoy, S. \& Dündar, T. (2019). Gebelerde sosyal destek durumu ve etkileyen faktörler. Journal of Human Sciences, 16(3), 736-745. doi:10.14687/jhs.v16i3.5618

Gebelikle ilgili yapılan araştırmalarda sosyal destek eksikliği olan kadınların gebeliğe uyumda da zorlandıkları ortaya çıkmıştır (Mckee et al., 2001; Swallow et al., 2004). Kadınların gebelik döneminde sosyal destek almaları anne ve bebek sağlığı açısından önemlidir. Sağlık profesyonelleri, kadınları gebelik döneminde sosyal destek alma durumları açısından değerlendirmelidir. Bunun yanı sıra sosyal destek sistemlerini harekete geçirme ve olumlu yöne çevirme konusunda annelere yardımcı olmalıdırlar. Özellikle kadınların gebelik ve doğum sonrası dönemde sosyal destek sistemlerini nasıl algıladıklarının bilinmesi önem taşımaktadır (Mermer vd, 2010). Sağlık profesyonelleri, gebelerin sosyal destek kaynaklarını daha etkili bir şekilde kullanmalarını sağlayarak kadınların gebeliğini en iyi şekilde geçirmelerini sağlamada daha etkin rol oynayabilirler. Bu nedenle bu araştırmanın amacı gebelerin sosyal destek durumunu ve etkileyen faktörleri belirlemektir. Böylelikle çalışma sonuçlarının literatüre katkı sağlaması ve sosyal desteğin önemi ile ilgili farkındalığın artması hedeflenmiştir.

\section{Yöntem}

\section{Araştırmanın Evreni ve Örneklemi}

Tanımlayıcı olarak planlanan bu araştırma bir Devlet Hastanesi'nin Non Stres Test (NST) polikliniğine başvuran gebeler ile yapılmıştır Araştırmanın evrenini çalışmanın yapıldığı hastanede 2016 yllında doğum yapan 4302 kadın oluşturmuştur. Örneklem grubunu evreni bilinen örneklem yöntemi kullanılarak hesaplanan 350 gebe oluşturmuştur. Örneklem grubu olasılıksız örnekleme yöntemlerinden biri olan gelişigüzel örnekleme yöntemi ile seçilmiştir. Araştırmaya katılmayı kabul eden, Türkçe konuşabilen ve anlayabilen gebe kadınlar çalışmaya dâhil edilmiştir. Soru formunu eksik dolduran kadınlar çalışmadan çıkarılmıştır.

\section{Veri Toplama Arac1}

Araştırma verilerinin toplanmasında literatür bilgileri kullanılarak hazırlanan soru formu ve Çok Boyutlu Algılanan Sosyal Destek Ölçeği (ÇBASDÖ) kullanılmıştır. Kişisel soru formu gebelerin tanıtıcı özellikleri ve gebelerin sosyal destek alma ile ilgili durumlarından oluşmaktadır (Çobanlar Akkaş, 2014; Gümüşdağ, 2014). Araştırma verileri NST polikliniğine gelen gebeler ile yüz yüze görüşme yöntemiyle toplanmıştır.

Kullanılan ölçeğin Türkçe’ye uyarlama, geçerlik ve güvenirliği yapılmıştır (Eker ve Akar, 1995; Eker vd, 2001). Ölçekte 12 madde vardır. Ölçek üç alt gruptan oluşmaktadır. Bunlar; aile (anne, baba, eş, çocuklar, kardeşler), özel insan (flört, nişanll, akraba, komşu, doktor) ve arkadaşlardır. Ölçeğin aileyi oluşturan alt grubu 3, 4, 8 ve 11. maddeleri, arkadaşlar grubu 6, 7, 9 ve 12. maddeleri ve özel insan grubu ise 1,2, 5 ve 10. maddeleri kapsamaktadır. Her bir maddeye verilen minimum puan 1, maksimum puan $7^{\prime}$ dir. Tüm alt ölçek puanlarının toplanması ile ölçeğin toplam puanı meydana gelmiştir. Ölçekten alınabilecek minimum puan 12 ve maksimum puan 84'dür. Puanın yüksek olması sosyal desteğin yüksek olduğunu, düşük olması ise desteğin algılanmadığını ya da destekten yoksun olduğunu belirtmektedir. Ölçeğin toplam Cronbach alfa katsayısı 0.89 , alt boyut Cronbach alfa katsayısı aile için 0.85 , arkadaş için 0.88 , özel insan için 0.92 olarak bulmuştur.

\section{Verilerin Analizi}

Veriler SPSS 18,0 paket programında değerlendirilmiştir. Verilerin analizinde, yüzdelik oranlar, aritmetik ortalama ve standart sapma gibi merkezi dağılım ölçütleri kullanılmıştır. Verilerin parametrik özellik taşıyıp taşımadığı homojenlik durumuna bakılarak değerlendirilmiştir. Veriler normal dağılım özelliği göstermediğinden, istatistiksel değerlendirmede Kruskal Wallis ve Mann Whitney U testi kullanılmıştır. İstatistisel anlamlılık değerlendirmesinde $\mathrm{p}<0.05$ düzeyi anlamlı kabul edilmiştir.

\section{Etik Yaklaşım}

Araşturmanın verilerinin toplanabilmesi devlet hastanesin'den resmi izin alınmıştır. Ayrıca gebelere araştırmanın amacı yazılı ve sözlü olarak açıklanmış, bilgilerin gizli tutulacağı belirtilmiş ve sözlü onam veren gebeler araştırmaya dahil edilmiştir. 
Toptaş, B., Aksu, H., Özsoy, S. \& Dündar, T. (2019). Gebelerde sosyal destek durumu ve etkileyen faktörler. Journal of Human Sciences, 16(3), 736-745. doi:10.14687/jhs.v16i3.5618

\section{Araştırmanın Sinırlılıkları}

$\mathrm{Bu}$ çalısma sonuçları yalnızca araştırmaya katılan gebeler ile genellenebilir. Gebelerin cevaplarının güvenilirliği, verdikleri bilgilerin doğruluğu ile sınırlıdır.

\section{Bulgular}

Tablo 1: Gebelerin Tanıtıcı Özelliklerine Göre Dağılımı ( $\mathrm{n}=350)$

\begin{tabular}{|c|c|c|}
\hline & Say1 & $\%$ \\
\hline \multicolumn{3}{|l|}{ Yaş grubu } \\
\hline 19 yaş ve altı & 26 & 7,4 \\
\hline $20-24$ yaş & 134 & 38,3 \\
\hline $25-29$ yaş & 107 & 30,6 \\
\hline 30 yaş ve üzeri & 83 & 23,7 \\
\hline \multicolumn{3}{|l|}{ Eğitim durumu } \\
\hline Okuryazar değil & 23 & 6,6 \\
\hline Okuryazar & 19 & 5,4 \\
\hline İlkokul & 46 & 13,2 \\
\hline Ortaokul & 140 & 40,0 \\
\hline Lise & 75 & 21,4 \\
\hline Üniversite ve üstü & 47 & 13,4 \\
\hline \multicolumn{3}{|l|}{ Eş eğitim durumu } \\
\hline Okuryazar değil & 17 & 4,9 \\
\hline Okuryazar & 22 & 6,3 \\
\hline İlkokul & 56 & 16,0 \\
\hline Ortaokul & 109 & 31,1 \\
\hline Lise & 110 & 31,4 \\
\hline Üniversite ve üstü & 36 & 10,3 \\
\hline \multicolumn{3}{|l|}{ Gelir durumu } \\
\hline Gelir giderden az & 143 & 40,9 \\
\hline Gelir gidere eşit & 150 & 42,9 \\
\hline Gelir giderden fazla & 57 & 16,2 \\
\hline \multicolumn{3}{|l|}{ Çalışma durumu } \\
\hline Evet & 52 & 14,9 \\
\hline Hayır & 298 & 85,1 \\
\hline \multicolumn{3}{|l|}{ Sağlık güvencesi } \\
\hline Var & 300 & 85,7 \\
\hline Yok & 50 & 14,3 \\
\hline \multicolumn{3}{|l|}{ Kronik hastalık } \\
\hline Var & 345 & 1,4 \\
\hline Yok & 5 & 98,6 \\
\hline \multicolumn{3}{|l|}{ Aile tipi } \\
\hline Çekirdek aile & 266 & 76,0 \\
\hline Geniş aile & 84 & 24,0 \\
\hline \multicolumn{3}{|c|}{ Gebeliği isteme durumu } \\
\hline Evet & 332 & 94,9 \\
\hline Hayır & 18 & 5,1 \\
\hline
\end{tabular}

Araştırmadaki kadınların \%38,3'ünün 20-24 yaş grubunda olduğu, \%40'ının ortaokul mezunu olduğu, eşlerinin \%31,4'ünün lise mezunu olduğu saptanmıştır. Gebelerin \%42,9'unun gelirinin giderine eşit olduğu, \%85,1'inin çalışmadığ1, \%85,7'sinin sağlık güvencesinin olduğu, \%98,6'sının kronik hastalığı olmadığ1, \%76'sının çekirdek aileye sahip olduğu belirlenmiştir. Kadınların \%94,9'u gebeliği istediklerini ifade etmiştir. Tanıtıcı bilgileri Tablo 1'de gösterilmiştir.

Gebelerin obstetrik özellikleri incelendiğinde, gebelik haftasının 35,4 $\pm 2,7$ ( $\min -\max =29$ -

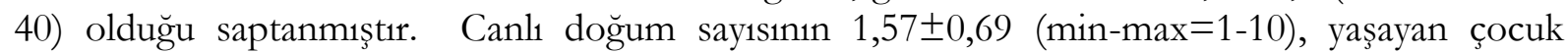

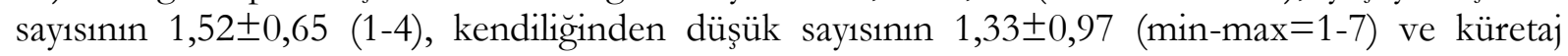
sayısının 1,21 $\pm 0,53$ (min-max $=1-3$ ) olduğu belirlenmiştir. 
Toptaş, B., Aksu, H., Özsoy, S. \& Dündar, T. (2019). Gebelerde sosyal destek durumu ve etkileyen faktörler. Journal of Human Sciences, 16(3), 736-745. doi:10.14687/jhs.v16i3.5618

Tablo 2: Gebelerin Sosyal Destek Alma Durumlarına İlişkin Dağılımı

\begin{tabular}{|c|c|c|}
\hline & Say1 & $\%$ \\
\hline \multicolumn{3}{|l|}{ Gebelik süresince eş tavrı } \\
\hline Çok iyi & 215 & 61,4 \\
\hline Iyi & 130 & 37,1 \\
\hline Kötü/ Cok kötü & 5 & 1,5 \\
\hline \multicolumn{3}{|l|}{ Kontrollere eşin gelme durumu } \\
\hline Gelmez/Gelemez & 77 & 22,0 \\
\hline Ara sira gelir & 123 & 35,1 \\
\hline Her zaman gelir & 150 & 42,9 \\
\hline \multicolumn{3}{|l|}{ Gebeliğin ilk kiminle paylaşıldığı } \\
\hline Eşimle & 305 & 87,1 \\
\hline Annemle/babamla & 23 & 6,6 \\
\hline Coçuk/Çocuklarımla & 2 & 0,6 \\
\hline Kardeș/Kardeşlerimle & 9 & 2,6 \\
\hline Kayınvalidemle/Kayınpederimle & 5 & 1,4 \\
\hline Arkadaşlarımla & 6 & 1,8 \\
\hline \multicolumn{3}{|l|}{ Gebe olduğunuzu ilk öğrendiğinizde ne hissettiğiniz } \\
\hline Sevindim & 301 & 86,0 \\
\hline Üzüldüm & 30 & 8,6 \\
\hline Hiçbir șey hissetmedim & 14 & 4,0 \\
\hline Şaşırdım, heyecanlandım & 5 & 1,4 \\
\hline \multicolumn{3}{|l|}{ Şu anda neler hissedildiği } \\
\hline Mutlu & 205 & 58,6 \\
\hline Heyecanlı & 115 & 32,9 \\
\hline Yorgun & 7 & 2,0 \\
\hline Mutsuz & 11 & 3,1 \\
\hline Karmaşık & 12 & 3,4 \\
\hline \multicolumn{3}{|l|}{ Eşiniz gebe olduğunuzu öğrendiğinde nasıl bir tepki verdi } \\
\hline Sevindi & 344 & 98,3 \\
\hline Üzüldü & 6 & 1,7 \\
\hline \multicolumn{3}{|l|}{ Gebeliğiniz aile büyükleriniz tarafından nasıl karşılandı } \\
\hline Sevindiler & 348 & 99,4 \\
\hline Üzüldüler & 2 & 0,6 \\
\hline \multicolumn{3}{|l|}{ Gebeliğiniz boyunca size en fazla kim/kimler destek oldu* } \\
\hline Eşim & 310 & 45,0 \\
\hline Annem/babam & 145 & 21,0 \\
\hline Kardeșlerim & 60 & 9,0 \\
\hline Kayınvalidem & 49 & 7,0 \\
\hline Arkadaşlarım & 49 & 7,0 \\
\hline Çoçuğum/çocuklarım & 46 & 6,0 \\
\hline Ebe/Hemşire/Doktor & 33 & 5,0 \\
\hline \multicolumn{3}{|c|}{$\begin{array}{l}\text { Gebeliğiniz süresince etrafınızdaki insanlarla ilgili genel olarak neler } \\
\text { hissetttiniz? * }\end{array}$} \\
\hline Her zaman benim yanımda olduklarını hissettim. & 272 & 65,0 \\
\hline Birçok insan için önemli olduğumu hissetttim. & 126 & 30,0 \\
\hline Bu süreçte bana destek olabilecek kimsenin olmadığını hissettim. & 18 & 5,0 \\
\hline \multicolumn{3}{|l|}{ Doğum sırasında yanınızda kimin olmasını istersiniz? * } \\
\hline Eşim & 234 & 47,0 \\
\hline Annem & 167 & 34,0 \\
\hline Kizkardessim-ablam & 54 & 10,0 \\
\hline Arkadaşım & 24 & 5,0 \\
\hline Kimse & 18 & 4,0 \\
\hline
\end{tabular}

*Birden fazla seçenek işaretlenmiştir. Yüzdeler toplam “ $n$ ” üzerinden hesaplanmıştır.

Gebelerin \%61,4'ü gebelik süresince kendilerine karşı eş tavrının çok iyi olduğunu, \%42,9’u gebelik süresince kontrollere eşlerinin her zaman geldiğini, \%87,1'i gebeliği illk önce eşleri ile paylaştıklarını belirtmişlerdir. Gebelerin \%86's1 gebe olduğunu öğrendiğinde sevindiğini, $\% 58,6$ 's1 şu an mutlu olduğunu, \%98,3'ü gebe olduğunu öğrendiğinde eşlerinin sevindiğini ve $\% 99,4$ 'ü aile büyüklerinin gebe olduklarını öğrendiğinde sevindiklerini ifade etmişlerdir. Gebelerin \%47'si gebelikte en fazla desteği eşlerinin verdiğini, \%65’i her zaman etrafindaki insanların yanında olduğunu hissettiğini belirtmiştir. Gebelerin \%47,7'si doğum sırasında eşinin yanında olmasını istemiştir (Tablo2). 
Toptaş, B., Aksu, H., Özsoy, S. \& Dündar, T. (2019). Gebelerde sosyal destek durumu ve etkileyen faktörler. Journal of Human Sciences, 16(3), 736-745. doi:10.14687/jhs.v16i3.5618

Tablo 3. Gebelerin ÇBASDÖ’den Aldıkları Puan Ortalamaları.

\begin{tabular}{|l|c|c|}
\hline \multicolumn{1}{|c|}{ Ölçek } & X \pm SD & Min-Max \\
\hline Özel insan toplam puanı & $16,25 \pm 8,46$ & $4-28$ \\
\hline Aile toplam puanı & $24,81 \pm 4,71$ & $8-28$ \\
\hline Arkadaş toplam puanı & $18,49 \pm 8,17$ & $4-28$ \\
\hline ÇBASDÖ toplam puanı & $59,60 \pm 15,9$ & $20-84$ \\
\hline
\end{tabular}

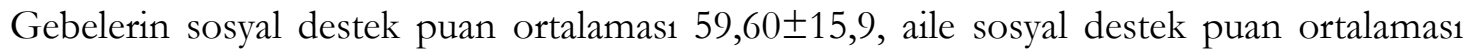
$24,81 \pm 4,71$, arkadaş sosyal destek puan ortalaması $18,49 \pm 8,17$ ve özel insan sosyal destek puan ortalaması 16,25 $\pm 8,46$ olarak bulunmuştur (Tablo 3).

Tablo 4. Gebelerin Tanıtıcı Özelliklere Göre ÇBASDÖ’den Aldıkları Puanların Karşılaştırılması

\begin{tabular}{|c|c|c|c|}
\hline \multicolumn{4}{|c|}{ Sosyal Destek Ölçeği Alt Boyutları } \\
\hline Özellikler & $\begin{array}{c}\text { Aile } \\
\mathrm{X} \pm \text { SD }\end{array}$ & $\begin{array}{c}\text { Arkadaş } \\
\mathrm{X} \pm \mathrm{SD}\end{array}$ & $\begin{array}{c}\text { Özel İnsan } \\
\text { X土SD }\end{array}$ \\
\hline $\begin{array}{l}\text { Yaş } \\
19 \text { yaş ve alt1 } \\
20-24 \text { yaş } \\
25-29 \text { yaş } \\
30 \text { yaş ve üzeri }\end{array}$ & $\begin{array}{l}25,57 \pm 4,46 \\
25,20 \pm 4,98 \\
24,27 \pm 4,98 \\
24,68 \pm 4,71 \\
\mathrm{KW}=5,630 \quad \mathrm{Sd}=3 \\
\mathrm{p}=0,131\end{array}$ & $\begin{array}{l}16,65 \pm 4,20 \\
18,87 \pm 7,58 \\
18,80 \pm 7,80 \\
18,48 \pm 8,88 \\
K W=1,061 \quad S d=3 \\
p=0,787\end{array}$ & $\begin{array}{l}17,76 \pm 8,47 \\
15,75 \pm 8,62 \\
16,15 \pm 8,09 \\
16,72 \pm 8,24 \\
K W=1,443 \quad \mathrm{Sd}=3 \\
\mathrm{p}=0,695\end{array}$ \\
\hline $\begin{array}{l}\text { Eğitim durumu } \\
\text { Okuryazar değil } \\
\text { Okuryazar } \\
\text { İlkokul } \\
\text { Ortaokul } \\
\text { Lise } \\
\text { Üniversite ve üstü } \\
\text { Test ve Sd } \\
\text { p değeri }\end{array}$ & $\begin{array}{l}23,26 \pm 4,61 \\
22,10 \pm 4,49 \\
23,71 \pm 4,49 \\
25,73 \pm 3,89 \\
24,92 \pm 5,13 \\
24,82 \pm 4,76 \\
K W=26,02 \mathrm{Sd}=5 \\
\mathrm{p}=\mathbf{0 , 0 0 0}\end{array}$ & $\begin{array}{l}14,43 \pm 9,81 \\
14,10 \pm 9,24 \\
17,08 \pm 8,71 \\
19,04 \pm 7,48 \\
19,26 \pm 7,89 \\
20,78 \pm 7,54 \\
K W=16,42 \mathrm{Sd}=5 \\
\mathrm{p}=\mathbf{0 , 0 0 6}\end{array}$ & $\begin{array}{l}14,56 \pm 7,54 \\
14,78 \pm 8,93 \\
15,06 \pm 8,66 \\
15,10 \pm 8,43 \\
18,58 \pm 8,49 \\
18,55 \pm 7,66 \\
K W=15,62 \mathrm{Sd}=5 \\
\mathrm{p}=\mathbf{0 , 0 0 8}\end{array}$ \\
\hline $\begin{array}{l}\text { Eş eğitim durumu } \\
\text { Okuryazar değil } \\
\text { Okuryazar } \\
\text { İlkokul } \\
\text { Ortaokul } \\
\text { Lise } \\
\text { Üniversite ve üstü } \\
\text { Test ve Sd } \\
\text { p değeri }\end{array}$ & $\begin{array}{l}23,41 \pm 4,61 \\
24,77 \pm 5,27 \\
24,57 \pm 4,89 \\
24,91 \pm 4,62 \\
24,89 \pm 4,81 \\
25,33 \pm 4,21 \\
\mathrm{KW}=5,041 \mathrm{Sd}=5 \\
\mathrm{p}=0,411\end{array}$ & $\begin{array}{l}14,35 \pm 9,37 \\
18,59 \pm 8,58 \\
16,53 \pm 8,45 \\
18,10 \pm 8,42 \\
19,63 \pm 7,41 \\
21,16 \pm 7,26 \\
K W=13,75 \mathrm{Sd}=5 \\
\mathrm{p}=\mathbf{0 , 0 1 7}\end{array}$ & $\begin{array}{l}13,11 \pm 7,51 \\
20,81 \pm 7,50 \\
12,08 \pm 7,80 \\
17,31 \pm 8,41 \\
15,82 \pm 8,58 \\
19,55 \pm 7,20 \\
K W=31,39 \mathrm{Sd}=5 \\
\mathrm{p}=\mathbf{0 , 0 0 0}\end{array}$ \\
\hline $\begin{array}{l}\text { Çalışma durumu } \\
\text { Evet } \\
\text { Hayır } \\
\text { Test } \\
\text { p değeri }\end{array}$ & $\begin{array}{l}25,28 \pm 4,52 \\
24,73 \pm 4,74 \\
\text { MWU: } 7517,500 \\
p=0,724\end{array}$ & $\begin{array}{l}21,71 \pm 6,08 \\
17,93 \pm 8,37 \\
\text { MWU: } 5819,500 \\
\text { p=0,004 }\end{array}$ & $\begin{array}{l}18,46 \pm 7,41 \\
15,87 \pm 8,58 \\
\text { MWU: } 6431,000 \\
\text { p=0,049 }\end{array}$ \\
\hline $\begin{array}{l}\text { Gelir durumu } \\
\text { Gelir giderden az } \\
\text { Gelir gidere eşit } \\
\text { Gelir giderden fazla } \\
\text { Test ve Sd } \\
\text { p değeri }\end{array}$ & $\begin{array}{l}24,13 \pm 4,95 \\
25,40 \pm 4,08 \\
24,96 \pm 5,44 \\
K W=10,10 \quad \mathrm{Sd}=2 \\
\mathrm{p}=\mathbf{0 , 0 0 6}\end{array}$ & $\begin{array}{l}17,03 \pm 8,24 \\
19,24 \pm 7,56 \\
20,19 \pm 9,03 \\
K W=10,55 \quad \mathrm{Sd}=2 \\
\mathbf{p}=\mathbf{0 , 0 0 5}\end{array}$ & $\begin{array}{l}16,15 \pm 7,84 \\
15,73 \pm 9,03 \\
17,89 \pm 8,36 \\
K W=2,405 \quad \mathrm{Sd}=2 \\
\mathrm{p}=0,300\end{array}$ \\
\hline
\end{tabular}

Yaş ile sosyal destek puan ortalaması arasında bir ilişki saptanmamıştır (sırasıyla $\mathrm{KW}=5,630, \mathrm{Sd}=3, \mathrm{p}>0,05 ; \mathrm{KW}=1,061, \mathrm{Sd}=3, \mathrm{p}>0,05 ; \mathrm{KW}=1,443, \mathrm{Sd}=3 \mathrm{p}>0,05)$. Gebelerin eğitim durumu ile sosyal destek ölçeği alt boyutları arasında anlamlı bir ilişki görülmüsstür (sırasıyla $\mathrm{KW}=26,02, \mathrm{Sd}=5, \mathrm{p}<0,05 ; \mathrm{KW}=16,42, \mathrm{Sd}=5, \mathrm{p}<0,05 ; \mathrm{KW}=15,62, \mathrm{Sd}=5, \mathrm{p}<0,05)$. Eş eğitim durumu ile arkadaş ve özel insan sosyal destek puanı arasında bir ilişki olduğu görülmüştür (sırasıyla $\mathrm{KW}=13,75, \mathrm{Sd}=5, \mathrm{p}<0,05 ; \mathrm{KW}=31,39 \mathrm{Sd}=5, \mathrm{p}<0,05)$. Gebelerin çalışma durumu ile 
Toptaş, B., Aksu, H., Özsoy, S. \& Dündar, T. (2019). Gebelerde sosyal destek durumu ve etkileyen faktörler. Journal of Human Sciences, 16(3), 736-745. doi:10.14687/jhs.v16i3.5618

arkadaş ve özel insandan algılanan sosyal destek puanı arasında anlamlı bir ilişki saptanmıştır (MWU: 5819,500, p<0,05; MWU: 6431,000, p<0,05). Gebelerin gelir durumu ile aile ve arkadaştan algilanan sosyal destek puanı arasında anlamlı bir ilişki saptanmıştır ( $K W=10,10$, $\mathrm{Sd}=2, \mathrm{p}<0,05 ; \mathrm{KW}=10,55, \mathrm{Sd}=2, \mathrm{p}<0,05)$.

\section{Tartışma}

Gebelerde sosyal destek durumunu ve bu durumunu etkileyen faktörleri belirlemek için yapılan bu çalışmada gebelerin çoğu gebelik süresince kendilerine karşı eş tavrının çok iyi olduğunu ve gebelik süresince kontrollere eşlerinin her zaman geldiğini belirtmiştir. Çobanlar Akkaş (2014) tarafindan yapılan çalışmada kadınların çoğu eş tavrının iyi olduğunu fakat eşlerinin bazen kendileri ile kontrole geldiklerini ifade ettikleri görülmüştür. Kadın bütün yaşam döneminde sosyal desteğe ihtiyaç duymaktadır. Gebelikte bu destek ihtiyacı daha da artmaktadır. Eşlerin vermiş olduğu destek gebelik süresince büyük önem taşımaktadır. Eşlerin kontrollere her zaman gelmiş olmaları sağılk profesyonellerinden gebelik süresince neler yapılacağı hakkında bilgi almalarını sağlayarak eşlerine gebelik süresince daha doğru bir şekilde yardım etmeleri açısından önemli olduğu söylenebilir.

Bu çalışmadaki kadınların çoğu gebeliği ilk önce eşleri ile paylaştıklarını, gebe olduğunu öğrendiğinde kendisinin, eşinin ve aile büyüklerinin bu duruma sevindiklerini belirtmişlerdir. Eşin ve aile büyüklerinin gebeliği öğrendiklerinde sevinmeleri gebeliği istediklerini göstermektedir ve bu durum gebelik boyunca kadına destek vermelerinde etkili olması açısından önemlidir. Bu araştırmadaki kadınların çoğu gebelikte en fazla desteği eşlerinden aldıklarını, gebelik boyunca her zaman etrafindaki insanların yanında olduğunu hissettiklerini ve doğum sırasında eşinin yanında olmasını istediklerini ifade etmiştir. Aynı şekilde Çobanlar Akkaş (2014), Yeşilçiçek Çalık ve Aktaş (2011) ve Eşen (2018)'nin çalışmalarında da kadınların çoğu en fazla desteği eşlerinden aldıklarını ifade etmişlerdir (Çobanlar Akkaş, 2014; Yeşilçiçek Çalık ve Aktaş, 2011; Eşen, 2018). Eşlerin baba olma sevinci ile eşlerini her açıdan desteklemeye çalıstıkları düşünülmektedir. Gebelik gibi hassas bir dönemde kadınların çoğunun etrafındaki insanların sürekli yanında olduğunu hissetmesi gebelik, doğum ve doğum sonu dönemde de oldukça önemlidir (Akbaş vd, 2008; Taşkın, 2016). Gebelik boyunca kadına verilen sosyal destek arttıkça anksiyete ve depresyon yaşama durumu azalmaktadır (Bennett al., 2004; Liu et al., 2013).

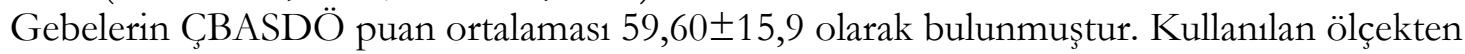
alınabilecek en yüksek puan 84 olduğu için bu çalışmadaki gebelerin sosyal destek puan ortalamasının orta düzeyden daha iyi olduğu görülmektedir. Bu çalışmadaki ÇBASDÖ puan ortalamasından daha fazla puanın alındığı çalışmalar bulunmaktadır (Mermer vd, 2010; Özdemir vd, 2010; Yeşilçiçek Çalık ve Aktaş, 2011; Gao et al., 2014; Güleç vd, 2014; Gümüşdağ, 2014; Nazari et al., 2015; Metin ve Pasinlioğlu, 2016; Azimi et al., 2018). Bu araştırmadaki ÇBASDÖ puanından daha az puanın alındığı çalışmalar da yer almaktadır (Şen vd, 2012; Yurdakul, 2018). $\mathrm{Bu}$ çalışmada gebelikte aileden algılanan sosyal destek puan ortalamasının diğer alt ölçek puanlarına oranla daha yüksek olduğu saptanmıştır. Bu çalışma ile benzer sonuçların olduğu çalışmalar bulunmaktadır (Mermer vd, 2010; Güleç vd, 2014; Yurdakul, 2018). Birçok gebelikte duygusal dalgalanmalar görülmektedir. Kadın bir an kendini mutlu neşeli hissederken kısa bir süre sonra kendini mutsuz ve güvensiz hisseder. Gebenin eşi ve aile üyelerinin bu dönemde gebe kadına destek vermesi önemlidir (Kızlkaya Beji, 2015).

Araştırma kapsamına aldığımız kadınların yaşları ile ÇBASDÖ’ nün alt boyutları arasında bir ilişki saptanmamıştır. Aynı şekilde Özdemir ve arkadaşları (2010) tarafından yapılan çalışmada kadınların yaşları ile ÇBASDÖ’ nün alt boyutları arasında bir ilişki olmadığı görülmüştür.

$\mathrm{Bu}$ araştırmada eğitim durumu ile alt ölçek puanları arasında bir fark saptanmıştır. Benzer şekilde Özdemir ve arkadaşlarının (2010) yaptıkları araştırmada da gebelerin eğitim düzeyi ile ÇBASDÖ’ nün 3 alt boyutları arasında fark bulunmuştur (Özdemir vd, 2010). Yurdakul (2016) tarafından yapılan çalışmada ise eğitim durumu ile özel insandan algılanan sosyal destek puanı arasında bir fark bulunmuştur. Bu çalışmada ve diğer çalışmaların sonucunda eğitim durumu 
Toptaş, B., Aksu, H., Özsoy, S. \& Dündar, T. (2019). Gebelerde sosyal destek durumu ve etkileyen faktörler. Journal of Human Sciences, 16(3), 736-745. doi:10.14687/jhs.v16i3.5618

yüksek olan gebelerde algilanan sosyal desteğin de fazla olduğu söylenebilir. Eğitim durumunun yüksek olması kadınların aile, arkadaş ve diğer insanlarla olan ilişkilerini olumlu yönde etkilediği düşünülebilir.

Araştırmaya aldığımız kadınların çalışma durumu ile arkadaş ve özel insan alt ölçek puanları arasında bir fark saptanmıştır. Özdemir ve arkadaşlarının (2010) araştırmasında da çalışma durumu ile arkadaş ölçek puanı arasında bir fark saptandığ1 görülmüştür (Özdemir vd, 2010). Bu araştırmada çalışan kadınların ölçek puanlarının daha fazla olduğu saptanmıştır. Çalışan kadınların iş nedeni ile sosyal çevrelerinin genişlemesi ve iş arkadaşlarına sahip olmaları gebelik döneminde sosyal destek alma durumlarının artmasını sağlamış olabilir.

Kadınların gelir durumu ile aile ve arkadaş alt ölçek puanları arasında bir fark saptanmıştır. Geliri giderine eşit ya da daha fazla olan kadınların sosyal desteğinin daha fazla olduğu görülmektedir. Aynı şekilde Metin ve Pasinlioğlu (2016) tarafindan yapılan çalışmada da gelir durumu ile sosyal destek alt ölçek grupları arasında bir fark olduğu belirlenmiştir. Gelir durumunun yeterli ve iyi olmasının sosyal desteği güçlendirdiği söylenebilir.

\section{Sonuç}

Çalışmaya alınan gebelerin sosyal destek düzeyinin ortanın üstünde olduğu ve en fazla sosyal desteği ailelerinden sağladıkları görülmüştür. Gebelerin sosyal destek alma düzeyleri gebe ve eşlerinin eğitim ve çalışma durumlarından olumlu yönde etkilenmektedir. Gebelik sürecinde gebelerin sosyal destek alma durumunun belirlenmesi, sosyal desteği yetersiz olan gebelere sağllk personeli tarafından sosyal destek verilmesi önerilmektedir. Ayrıca gebe, eş ve ailesinin, gebelik dönemindeki sosyal destek ile ilgili bilgi eksiklikleri giderilmelidir.

\section{Kaynaklar}

Akbaş, A., Vırıt, O., Kalenderoğlu, A., Savaş, AH., Sertbaş, G. (2008). Gebelikte sosyodemografik değişkenlerin kayg1 ve depresyon düzeyiyle ilişkisi. Nöropsikiyatri Arşivi, 45(3), 85-91.

Aktas, S., Yeşilçiçek Çalık, K. (2015). Factors affecting depression during pregnancy and the correlation between social support and pregnancy depression. Iranian Red Crescent Medical Journal, 17(9).

Azimi, M., Fahami, F., Mohamadirizi, S. (2018). The relationship between perceived social support in the first pregnancy and fear of childbirth. Iranian Journal of Nursing and Midwifery Research, 23(3), 235-239. doi: 10.4103/ijnmr.IJNMR_170_16

Bennett, HA., Einarson, A., Taddio, A., Koren, G., Einarson, TR. (2004). Clin Drug Investig, 24(3), 157-179.

Çobanlar Akkaş, S. (2014). Gebelik döneminde eşler arası uyum. Aydın Adnan Menderes Üniversitesi. Yüksek Lisans Tezi. Sağlık Bilimleri Enstitüsü. Aydın. 129.

Eker, D., Akar, H. (1995). Çok boyutlu algylanan sosyal destek ölçeğinin gözden geçirilmiş formunun faktör yapıs1, geçerlik ve güvenirliği. Türk Psikizyatri Dergisi, 10(34), 45-55.

Eker, D., Arkar, H., Yaldız, H. (2001). Factorial structure, validity, and reliability of revised form of the multidimensional scale of perceived social support. Türk Psikiyatri Dergisi, 12, 17-25.

Eşen, EN. (2018). Gebelikte ruhsal iyi oluş ve eş uyumunun fizyolojik iyi olma ile ilişkisi. Üsküdar Üniversitesi. Yüksek Lisans Tezi. Sosyal Bilimler Enstitüsü. İstanbul. 105.

Gao, L., Sun, K., Chan, SW. (2014). Social support and parenting self-efficacy among chinese women in the perinatal period. Midwifery, 30(5), 532-538.

Güleç, D., Öztürk, R., Sevil, Ü., Kazandı, M. (2014). Gebelerin yaşadıkları doğum korkusu ile algiladikları sosyal destek arasındaki ilişki. Turkiye Klinikleri Journal of Gynecology and Obstetrics, 24(1), 36-41.

Gümüşdağ M. (2014). Gebelerde evlilik uyumu ve sosyal destek arasındaki ilişki. Atatürk Üniversitesi. Yüksek Lisans Tezi. Sağlık Bilimleri Enstitüsü. Erzurum. 52. 
Toptaş, B., Aksu, H., Özsoy, S. \& Dündar, T. (2019). Gebelerde sosyal destek durumu ve etkileyen faktörler. Journal of Human Sciences, 16(3), 736-745. doi:10.14687/jhs.v16i3.5618

Kızılkaya Beji, N., Aydın Özkan, S. (2015). Gebelikte görülen fizyolojik/psikolojik değişiklikler. Nezihe Kizılkaya Beji Ed. İstanbul, Nobel Tip Kitapevleri, 227-244.

Liu, L., Setse, R., Grogan, R., Powe, NR., Nicholson, WK. (2013). The effect of depression symptoms and social support on black-white differences in health-related quality of life in early pregnancy: The Health Status in Pregnancy (HIP) Study. BMC Pregnancy Childbirth, $13,125$.

Mckee, MD., Cunningham, M., Jankowski, KR., Zayas, L. (2001). Health-related functional status in pregnancy: relationship to depression and social support in a multi-ethnic population. Obstet Gynecol, 97(6), 988-993.

Mermer, G., Bilge, A., Yücel, U., Çeber, E. (2010). Gebelik ve doğum sonrası dönemde sosyal destek algisı düzeylerinin incelenmesi. Psikiyatri Hemşirelĭgi Dergisi, 1(2), 71-76.

Metin, A., Pasinlioglu, T. (2016) The relationship between perceived social support and prenatal attachment in pregnant women. Uluslararası Hakemli Kadin Hastalıklar ve Anne Cocuk Sağhl̆ğ Dergisi, 5, 49-66.

Nazari, M., Ghasemi, S., Vafaei, H., Fararouei, M. (2015). The perceived social support and its relationship with some of the demographic characteristics in primigravida pregnant women. International Journal of Nursing and Midwifery, 7(9), 141-145.

Okanlı, A., Tortumluoğlu, G., Kırpınar, İ. (2003). Gebe kadınların ailelerinden algıladıkları sosyal destek ile problem çözme becerileri arasındaki ilişki. Anadolu Psikizyatri Dergisi, 4, 98-105.

Özdemir, F., Bodur, S., Nazik, E., Nazik, H., Kanbur, A. (2010). Hiperemezis gravidarum tanıs1 alan gebelerin sosyal destek düzeyinin belirlenmesi. TAF Preventive Medicine Bulletin, 9(5), 463-470.

Swallow, BL., Lindow, SW., Masson, EA., Hay, DM. (2004). Psychological health in early pregnancy: relationship with nausea and vomiting. J Obstet Gynaecol, 24(1), 28-32.

Şen, S., Egelioğlu, N., Saruhan, A. (2012). The relationship between migration and depression, anxiety level and social support in pregnancy. International Journal Of Human Sciences, 9(2), $1-13$.

Taşkın, L. (2016). Gebeliğin Psikososyal ve kültürel boyutu: Doğum ve kadın sağlığı hemşireliği 13.baski. Ankara:Akademisyen Tip Kitapevi, 218-227.

Timur, S., Şahin, HN. (2010). Women's social support preferences and experiences during labor. Hemsirelikete Araștırma Gelistirme Dergisi, 12(1), 29-40.

Yeşilçiçek Çalık, K., Aktaş S. (2011). Gebelikte depresyon: sıklık, risk faktörleri ve tedavisi. Psikiyatride Güncel Yaklasimlar-Current Approaches in Psychiatry, 3(1), 142-162.

Yıldırım, İ. (1997). Algılanan sosyal destek ölçeği’nin geliştirilmesi güvenirliği ve geçerliği. Hacettepe Üniversitesi Eğitim Fakültesi Dergisi, 13, 81-87.

Yurdakul, M. (2018). Perceived social support in pregnant adolescents in mersin area in Turkey. Pakistan Journal of Medical Sciences, 34(1), 115-120.

\section{Extended English Summary}

Pregnancy and postpartum period is a physiological process with significant biological changes, besides it is a complex sociological and psychological situation. One of the important factors affecting adaptation and coping of pregnancy and postpartum period is the situation of women's getting social support during pregnancy and postpartum period. Women who receive social support during pregnancy spend their pregnancy in more positive emotions and gain the role of motherhood more quickly. It is important to know how women perceive social support systems during pregnancy and postpartum period. The aim of this study is to determine social support situation of pregnant women and affecting factors.

This descriptive study has been conducted with pregnant women who applied to NonStress Test polyclinic of a state hospital. Universe of the study consisted of 4302 women who 
Toptaş, B., Aksu, H., Özsoy, S. \& Dündar, T. (2019). Gebelerde sosyal destek durumu ve etkileyen faktörler. Journal of Human Sciences, 16(3), 736-745. doi:10.14687/jhs.v16i3.5618

gave birth in 2016 in hospital where the study was conducted. Sample group consisted of 350 pregnant women that was calculated by using the universe known sampling method. Individuals have been selected by random sampling method which is one of the probabilistic sampling methods. Personal questionnaire prepared by researchers using literature and Multidimensional Perceived Social Support Scale have been used for collection of research data. The personal questionnaire consists of information about characteristics and social support status of pregnant women. Multidimensional Scale of Perceived Social Support is a scale consisting of 12 items. The scale is consist of 3 groups; family (mother, father, spouse, children, siblings), special people (flirt, engaged, relative, neighbor, doctor) and friends, every group have four items. Each items have been scored between 1-7. Lowest score of the scale is 12 and highest score is 84 . High scores obtained from the scale indicate that perceived social support is high, while low scores indicate that support is not perceived or women have lack of support. Research data have beeen collected through face-to-face interviews. Percentage ratios, arithmetic mean and standard deviation, Kruskal Wallis variance analysis and Mann Whitney $U$ test have been used in analysis of data. Official permission has been obtained from the state hospital to collect data of the study. Verbal consent has been obtained from pregnant women.

Of pregnant women $\% 61,4$ have stated that their spouses' attitude towards them was very good during pregnancy, $\% 42,9$ have stated that their spouses always came to their controls during pregnancy and $\% 87,1$ have stated that they shared the pregnancy with their spouses first. Pregnant women have stated that $99.4 \%$ of their family elders, $98.3 \%$ of their spouses, $86 \%$ of themselves became happy when they first learned the pregnancy. Of pregnant women $47 \%$ have stated that their spouses were the most supportive person during pregnancy and $47.7 \%$ have stated that they wanted the spouses to be with them at birth. The mean number of multidimensional perceived social support of pregnant women is 59,60 $\pm 15,9$. It has been found that the mean social support score of the family is higher. A significant relationship has been found between educational status of the pregnant women and sub-dimensions of multidimensional perceived social support scale. There is a significant relationship between spouses' education status and perceived social support score of friend and private person. A significant relationship has been found between working status of pregnant women and perceived social support score of friend and private person. A significant relationship has been found between income status of pregnant women and perceived social support score of family and friend.

According to the study results, most of pregnant women have stated that their spouses' attitude towards them was very good during pregnancy, their spouses always came to their controls during pregnancy and they shared the pregnancy with their spouses first. It has been determined that most of pregnant women received most of the support from their spouses during pregnancy and they wanted to be with their spouses at birth. It has been observed that social support level of pregnant women is above the middle level and they provided the most of social support from their families. Social support level of pregnant women is positively affected by education and working conditions of pregnant women and their spouses.

Healthcare team members should be able to activate the spouses, family, friend environment in order to evaluate pregnant women with insufficient social support and get them appropriate support. It is thought that healthcare team members should use guidelines and scales that can evaluate social support status of pregnant women. In addition, it can be suggested that new studies should be carried out with other pregnant groups with different socio-demographic characteristics. 